\title{
Algoritma Pemrograman dan Struktur Data
}

\author{
Erwan suganda Putra \\ 195120045 \\ Fakultas Komputer \\ erwansuganda.student@umitra.ac.id
}

\begin{abstract}
Struktur data adalah untuk mengorganisasikan data sedemikian rua sehingga implemental ( penerapan ) ataupemeliharaanlogika program menjadilebihterstruktur.Dalamistilahilmukomputer, struktur data adalahcarapenyimpanan ,pengorganisasian, danpengaturan data di dalam media penyimpanankomputersehingga data tersebutdapatdigunakansecaraefisien.

Bahasapemprograman turbo pascalsecaraumum yang dilakukan program adalahkumpulaninstruksiatauperintah yang disusunsedemikianrupasehinggamempunyaiuritanlogika yang tepatuntukmenyelesaikansuatupersoalan.

Yaitu, salahsatuaplikasiprogram tersebutadalah turbo pascal,materikuliahstruktur data akandisampaikandenganmengunakanlogikaterbopascal.

\section{* AlgoritmadanStruktur Data}

algoritmamerupakanjantungsemua program yang merupakansemuaurutanlangkahsistematisdandirancanguntukmenyelesuaikansuatumasala hspesifikdandenganusaha yang paling minimal.
\end{abstract}

- KarakteristikAlgoritma :

$>$ Input

$>$ Output

$>$ Definite (jelas)

$>$ Efective

$>$ Terminate (berakhit) 


\section{Langkah - langkah pembuatan program}

$>$ Mendefisikanpermasalahan

Ditahapaninikitaharusmengertidenganbaikmengenaipermasalahan yang ingin di selesaikan

$>$ Membuatrumusanuntukpemecahanmasalah

Disinikitadapatmembuatrumusanalgoritmauntukpemecahanmasalahtersebut.dapatdisusun dalambentukpseudocodemaupun flowchart

Ex:A.pseudocode

Mulai

Input ( Bilangan 1)

Input ( Bilangan 2)

Hasil = Bilangan $1+$ Bilangan 2

Output ( Hasil )

Selesai

\section{Flowchart}
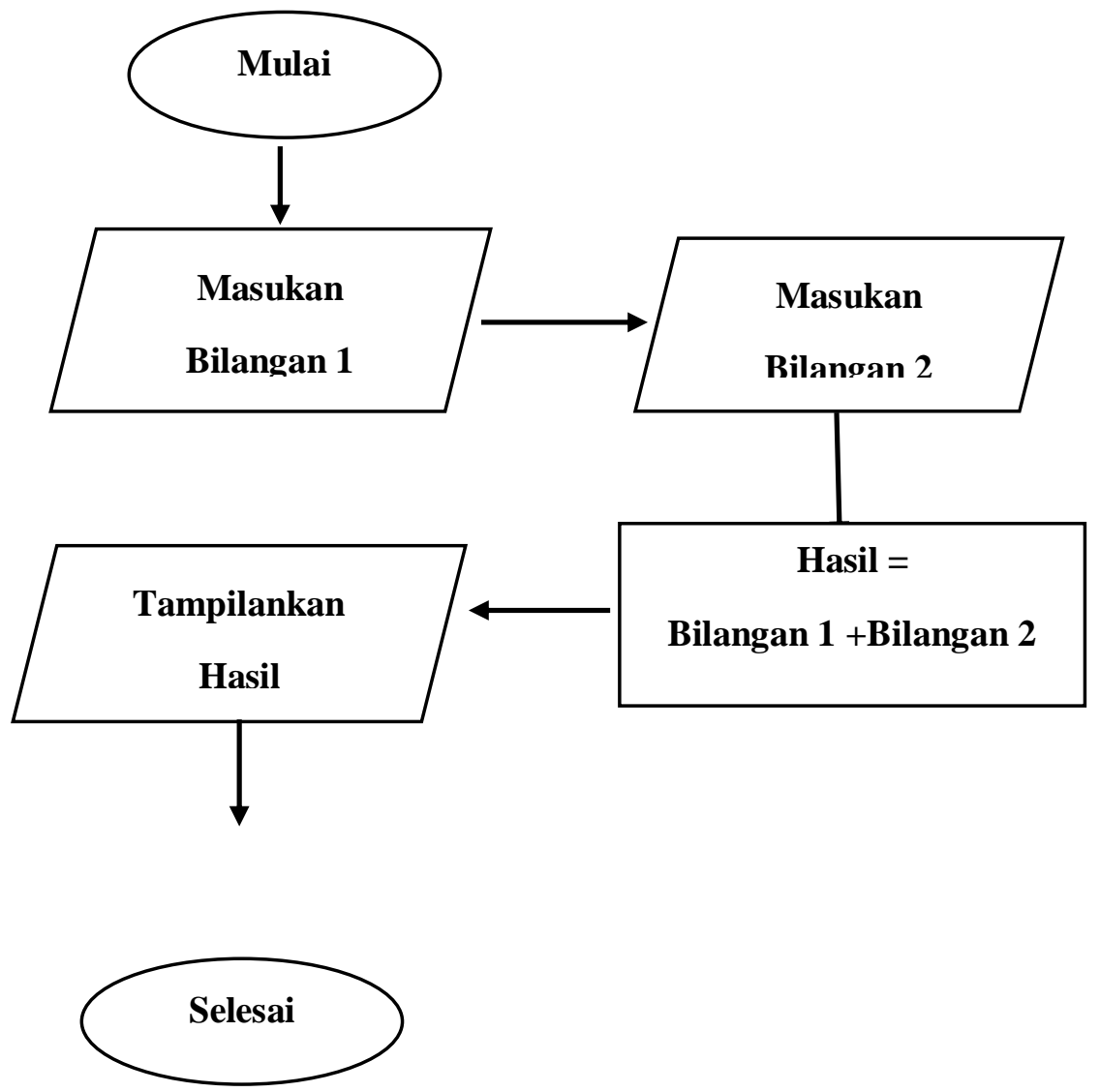
- Contoh:

MenghitungLuasSegitiga

AlgoritmaMenghitungLuasSegitiga

Analisis :

$>$ Input : a (alas) dan t (tinggi)

$>$ LuasSegitiga $=\mathrm{a}^{*} \mathrm{t} / 2$

Algoritma :

$>$ Masukannilai alas (a) dannilaitinggisegitiga (t)

$>$ Makauntukmenghitungluasdigunakanrumus alas dengantinggi yang sudahditentukan

$>$ RumusuntukmenghitungLuasSegitigayaitu $\mathrm{L}=1 / 2 * \mathrm{a} * \mathrm{t}$

$>$ Nilai L (Luas) akandicetaksebagai output keperangkat output (keluaran)

Flowchart MenghitungLuasSegitiga

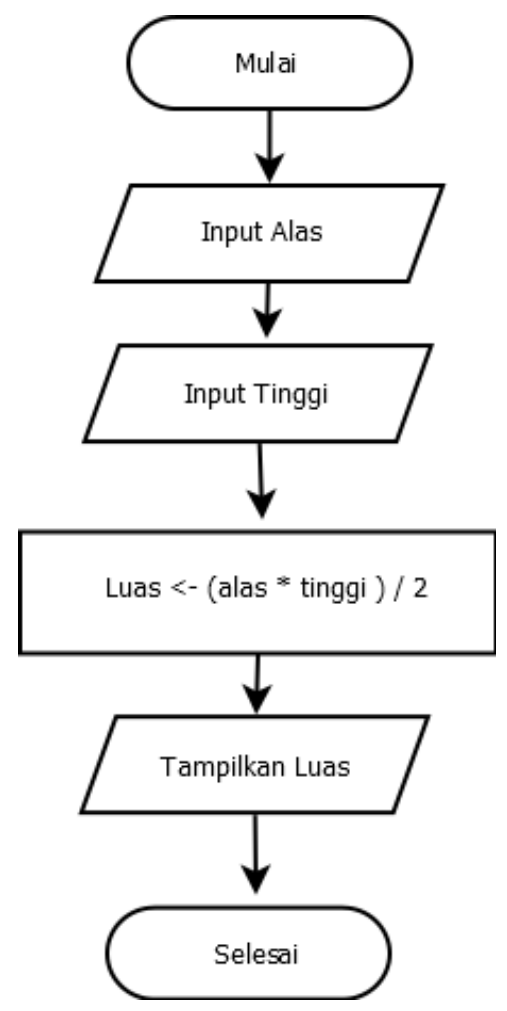




\section{A. PENDAHULUAN}

Materikuliah section 01 membahastentangalgoritmapemprogramandanstruktur data dalamsuatualgoritmamerupakanjantungsemua program yang merupakansemuaurutanlangkahsistematisdandirancanguntukmenyelesuaikansuatumasala hspesifikdandenganusaha yang paling minimal.

\section{B. PEMBAHASAN / STUDI KASUS}

\section{$\checkmark$ PengertianStruktur Data}

Struktur data adalahuntukmengorganisasikan datasedemikianrupasehingga implemental ( penerapan ) ataupemeliharaanlogika program menjadilebihterstruktur.Dalamistilahilmukomputer, struktur data adalahcarapenyimpanan ,pengorganisasian, danpengaturan data di dalam media penyimpanankomputersehingga data tersebutdapatdigunakansecaraefisien.

\section{$\checkmark$ Bahasapemprograman turbo pascal}

secaraumum yang dilakukan program adalahkumpulaninstruksiatauperintah yang disusunsedemikianrupasehinggamempunyaiuritanlogika yang tepatuntukmenyelesaikansuatupersoalan

\section{$\checkmark \quad$ Langkah - langkahpembuatan program}

a. Mendefisikanpermasalahan

Ditahapaninikitaharusmengertidenganbaikmengenaipermasalahan yang ingin di selesaikan

b. Membuatrumusanuntukpemecahanmasalah

Disinikitadapatmembuatrumusanalgoritmauntukpemecahanmasalahtersebut.dapatdisusun dalambentukpseudocodemaupun flowchart

Ex:A.pseudocode

Mulai

Input ( Bilangan 1)

Input ( Bilangan 2)

Hasil = Bilangan $1+$ Bilangan 2

Output ( Hasil )

Selesai 


\section{ID SECURITY}

QWTD44112377-ASP-524414475

\section{KESIMPULAN}

KesimpulandarimateriiniadalahDalamistilahilmukomputer, struktur data adalahcarapenyimpanan ,pengorganisasian, danpengaturan data di dalam media penyimpanankomputersehingga data tersebutdapatdigunakansecaraefisien.

\section{E. DISKUSI}

Sayabersamatemansayabernama redo mendiskusikantentangpengertianAlgoritmaPemrogramandanStruktur Datainidengansangatbaikhasildiskusidarimateriiniadalahuntukmengorganisasikan datasedemikianrupasehingga implemental ( penerapan ) ataupemeliharaanlogika program menjadilebihterstruktur.Dalamistilahilmukomputer, struktur data adalahcarapenyimpanan ,pengorganisasian, danpengaturan data di dalam media penyimpanankomputersehingga data tersebutdapatdigunakansecaraefisien 


\section{F. REFERENCE}

[1] O. M. Febriani and A. S. Putra, "Sistem Informasi Monitoring Inventori Barang Pada Balai Riset Standardisasi Industri Bandar Lampung," J. Inform., vol. 13, no. 1, pp. 90-98, 2014.

[2] A. S. Putra, "Paperplain: Execution Fundamental Create Application With Borland Delphi 7.0 University Of Mitra Indonesia," 2018.

[3] A. S. Putra, "2018 Artikel Struktur Data, Audit Dan Jaringan Komputer,' 2018.

[4] A. S. Putra, "ALIAS MANAGER USED IN DATABASE DESKTOP STUDI CASE DB DEMOS."

[5] A. S. Putra, "COMPREHENSIVE SET OF PROFESSIONAL FOR DISTRIBUTE COMPUTING."

[6] A. S. Putra, "DATA ORIENTED RECOGNITION IN BORLAND DELPHI 7.0."

[7] A. S. Putra, "EMBARCADERO DELPHI XE 2 IN GPU-POWERED FIREMONKEY APPLICATION."

[8] A. S. Putra, "HAK ATAS KEKAYAAN INTELEKTUAL DALAM DUNIA TEKNOLOGY BERBASIS REVOLUSI INDUSTRI 4.0."

[9] A. S. Putra, "IMPLEMENTASI PERATURAN PERUNDANGAN UU. NO 31 TAHUN 2000 TENTANG DESAIN INDUSTRI BERBASIS INFORMATION TECHNOLOGY."

[10] A. S. Putra, "IMPLEMENTATION OF PARADOX DBASE."

[11] A. S. Putra, "IMPLEMENTATION
OF TRADE SECRET CASE STUDY SAMSUNG MOBILE PHONE."

[12] A. S. Putra, "IMPLEMENTATION PATENT FOR APPLICATION WEB BASED CASE STUDI WWW. PUBLIKLAMPUNG. COM."

[13] A. S. Putra, "IMPLEMENTATION SYSTEM FIRST TO INVENT IN DIGITALLY INDUSTRY."

[14] A. S. Putra, "MANUAL REPORT \& INTEGRATED DEVELOPMENT ENVIRONMENT BORLAND DELPHI 7.0."

[15] A. S. Putra, "PATENT AS RELEVAN SUPPORT RESEARCH."

[16] A. S. Putra, "PATENT FOR RESEARCH STUDY CASE OF APPLE. Inc."

[17] A. S. Putra, "PATENT PROTECTION FOR APPLICATION INVENT."

[18] A. S. Putra, "QUICK REPORT IN PROPERTY PROGRAMMING."

[19] A. S. Putra, "REVIEW CIRCUIT LAYOUT COMPONENT REQUIREMENT ON ASUS NOTEBOOK."

[20] A. S. Putra, "REVIEW TRADEMARK PATENT FOR INDUSTRIAL TECHNOLOGY BASED 4.0."

[21] A. S. Putra, "TOOLBAR COMPONENT PALLETTE IN OBJECT ORIENTED PROGRAMMING."

[22] A. S. Putra, "WORKING DIRECTORY SET FOR PARADOX 7."

[23] A. S. Putra, "ZQUERY CONNECTION IMPLEMENTED PROGRAMMING STUDI CASE 


\section{PT.BANK BCA Tbk."}

[24] A. S. Putra, D. R. Aryanti, and I. Hartati, "Metode SAW (Simple Additive Weighting)

sebagai Sistem Pendukung Keputusan Guru Berprestasi (Studi Kasus: SMK Global Surya)," in Prosiding Seminar Nasional Darmajaya, 2018, vol. 1, no. 1, pp. 85-97.

[25] A. S. Putra and O. M. Febriani, "Knowledge Management Online Application in PDAM Lampung Province," in Prosiding International conference on Information Technology and Business (ICITB), 2018, pp. 181-187.

[26] A. S. Putra, O. M. Febriani, and B. Bachry, "Implementasi Genetic Fuzzy System Untuk Mengidentifikasi Hasil Curian Kendaraan Bermotor Di Polda Lampung," SIMADA (Jurnal Sist. Inf. dan Manaj. Basis Data), vol. 1, no. 1, pp. 21-30, 2018.

[27] A. S. Putra, H. Sukri, and K. Zuhri, "Sistem Monitoring Realtime Jaringan Irigasi Desa (JIDES) Dengan Konsep Jaringan Sensor Nirkabel," IJEIS (Indonesian J. Electron. Instrum. Syst., vol. 8, no. 2, pp. 221232.

[28] D. P. Sari, O. M. Febriani, and A. S. Putra, "Perancangan Sistem Informasi SDM Berprestasi pada SD Global Surya," in Prosiding Seminar Nasional Darmajaya, 2018, vol. 1, no. 1, pp. 289-294. 